\title{
DESCOMPASSOS DA REFORMA PSIQUIÁTRICA: A SAÚDE MENTAL EM UM MUNICÍPIO DO INTERIOR DO PARANÁ
}

\author{
MISMATCHES OF THE PSYCHIATRIC REFORM: THE MENTAL HEALTH IN \\ A CITY OF PARANÁ
}

Marcela Pereira Rosa e Gustavo Zambenedetti

Universidade Estadual do Centro-Oeste - Paraná

\section{RESUMO}

Este trabalho teve como objetivo caracterizar a rede de atenção em saúde mental em um município de pequeno porte no interior do Estado do Paraná. Trata-se de uma pesquisa de caráter qualitativo e exploratório, tendo como técnica de coleta de dados a entrevista semiestruturada. $\mathrm{O}$ grupo de sujeitos participantes da pesquisa foi constituído por representante da gestão da Secretaria Municipal de Saúde e trabalhadores vinculados à atenção primária, ambulatorial e hospitalar. A partir dos dados encontrados, tratamos de alguns dos desafios que se fazem presentes na trajetória de construção de modelos de assistência condizentes com as diretrizes da atenção psicossocial. Pudemos observar que ao invés de uma rede, existem no município alguns pontos de atenção, os quais nem sempre apresentam-se de modo articulado. O cuidado centrava-se no binômio hospital-ambulatório, sendo que o atendimento ofertado tinha um caráter marcadamente medicamentoso e fundamentado na perspectiva biomédica. Notamos a existência de um modelo médico-centrado em detrimento de uma prática usuáriocentrada. Neste sentido, apontamos para um descompasso existente na trajetória da Reforma no cenário brasileiro, pois se por um lado muito se avançou em alguns municípios e Estados, em outros a Reforma parece não exercer um impacto significativo em direção à consolidação de um novo modelo de atenção.

Palavras-chave: saúde mental, rede de atenção, atenção psicossocial, Reforma Psiquiátrica, desinstitucionalização

\begin{abstract}
This work aimed to characterize the mental health care network in a small city in the state of Paraná. This is a qualitative and exploratory research, which used the semi-structured interview as data collection technique. The group of the research subjects consisted of a municipal Health Department management representative and workers linked to primary, ambulatory and hospital care. From the data obtained, we dealt with some of the challenges that arise in the path of care models construction consistent with the guidelines of psychosocial care. We were able to observe that instead of a network, there are some care centers in the city, which do not always present themselves articulately. The care was focused on the binominal ambulatory-hospital and the assistance offered had a markedly medicinal character, grounded in biomedical perspective. We noticed the existence of a doctor-centered model to the detriment of a user-centered practice. This way, we point to a mismatch on the Reform trajectory in the Brazilian scenario, because if on the one hand there were a lot of advances in some cities and states, in others places the Reform does not seem to have a significant impact towards the consolidation of a new care model.
\end{abstract}


Key-words: mental health, care network, psychosocial care, Psychiatric Reform, deinstitutionalization

\section{INTRODUÇÃO}

Pensar e implementar novas práticas e novos modos de relacionar-se com a loucura vem sendo um grande desafio desde o início dos movimentos que colocaram em pauta a luta pela reforma psiquiátrica. Em que pese os avanços que alcançamos em relação às antigas práticas de tratamento da loucura, impera a necessidade de que atentemos para os desafios e dificuldades que se impõem à consolidação de um novo modelo de atenção à saúde mental. Se por um lado é inegável que grandes conquistas vêm sendo obtidas desde a quebra das correntes que aprisionavam o louco e a loucura, por outro, há que se questionar e compreender que elos desta corrente ainda subsistem, para que possamos continuar avançando no sentido de propor estratégias e ações que contribuam para a construção e consolidação de um cuidado em saúde que tenha como eixo estruturante a defesa da vida (Campos, 1997).

Tendo isso em vista e considerando a necessidade de estimularmos cada vez mais as discussões no campo da saúde mental, demos início a uma pesquisa que tinha por objetivo caracterizar a rede de atenção em saúde mental em um município de pequeno porte no interior do Estado do Paraná. A partir dos dados desta investigação, trataremos neste trabalho de alguns dos tantos desafios que se fazem presentes na trajetória de construção de modelos de assistência condizentes com as diretrizes da atenção psicossocial.

\section{QUEBRAR AS CORRENTES, DERRUBAR OS MUROS, CONSTRUIR NOVAS POSSIBILIDADES}

Até a década de 1980 no Brasil, a assistência às pessoas em sofrimento psíquico possuía caráter hospitalocêntrico e manicomial (Amarante, 1995; Resende, 2001). No modelo manicomial, os considerados 'loucos' - ou seja, aqueles que destoavam dos padrões de normalidade estabelecidos socialmente - eram mantidos encarcerados em condições verdadeiramente sub-humanas. Foi em face a tais condições, que feriam gravemente os direitos humanos dos internos, que tiveram início diferentes movimentos que reivindicavam a reforma psiquiátrica. Na história do tratamento da loucura, se as correntes que aprisionavam 
os loucos já haviam sido rompidas por Pinel, novos desafios se impunham e fazia-se necessário derrubar de vez os muros dos hospitais psiquiátricos.

Dentre os movimentos pela reforma, no âmbito internacional, Amarante (2007) menciona a Comunidade Terapêutica, a Psicoterapia Institucional, a Psiquiatria de Setor, a Psiquiatria Preventiva e a experiência de reforma italiana ${ }^{1}$. No Brasil, a Reforma Psiquiátrica tem seu início no final da década de 1970 com o Movimento dos Trabalhadores em Saúde Mental, o qual passa a se configurar, a partir da segunda metade da década de 1980, como Movimento Nacional da Luta Antimanicomial. Esse processo tem sua inspiração na experiência de reforma italiana, cujo principal representante foi Franco Basaglia. A proposta tinha como fundamento a noção de desinstitucionalização e, entre as suas estratégias, o fechamento do Hospital Psiquiátrico e a criação de serviços territoriais substitutivos.

Este novo modelo de assistência valoriza a permanência da pessoa em sofrimento psíquico no território. O bairro, a família, a comunidade e as unidades de saúde encravadas no território são identificados como locais privilegiados para esse tratamento (Lancetti e Amarante, 2009). Ao tratar deste modelo, o de atenção psicossocial, Costa-Rosa (2000) atenta também para a valorização do sujeito, que não desconsiderado em sua individualidade, passa a ter papel fundamental no tratamento.

Após um momento inicial de denúncias das violências asilares, de um momento posterior de proposição de alternativas, o período pós 2001 - ano em que foi aprovada a lei 10.216, que reorienta a atenção em saúde mental no Brasil - passou a ser caracterizado pela expansão da chamada rede de atenção. Dados do Ministério da Saúde (Brasil, 2012), demonstram que o número de CAPS passou de 295, em 2001, para 1742, em 2011 (Brasil, 2012), chegando em 2013 a mais de duas mil unidades. As residências terapêuticas já beneficiavam, em 2011, cerca de 3470 pessoas, passando de 85 residências terapêuticas implantadas em 2001 para 625 em 2011 (Brasil, 2012).

Diante da nova proposta e da descentralização, que desloca para os municípios a gestão de seus recursos e demandas, em várias localidades do Brasil vão surgindo diferentes serviços, estratégias e ações que constituem a atenção à saúde mental e configuram diferentes modos de operacionalizar a rede de assistência mediante as diversas possiblidades de articulação entre os dispositivos que a compõem. Neste contexto, os desafios e as potencialidades de cada uma destas realidades municipais desenham configurações singulares de redes de atenção, como já indicado em outros estudos (Zambenedetti, Perrone, 2008). Daí

\footnotetext{
${ }^{1}$ A respeito da diferenciação entre estes movimentos conferir Amarante (2007) e Desviat (1994).
} 
a necessidade de olharmos para os diferentes contextos no intuito de compreender que características vão se apresentando em cada modo de produzir cuidado no campo da saúde mental.

Diante disso, realizamos uma pesquisa que teve por objetivo compreender como ocorre a constituição da atenção em saúde mental em um município da região Centro-Sul do Estado do Paraná, tendo como foco sua articulação com os ideais da Reforma Psiquiátrica. Buscamos investigar quais eram as ações e serviços ofertados em saúde mental no município, bem como quais eram as demandas e os desafios para a consolidação da atenção, verificando se as políticas em saúde mental no município eram consoantes às diretrizes da política nacional de saúde mental.

\section{MÉTODO DE PESQUISA}

Esta pesquisa teve caráter qualitativo e exploratório. Minayo (2006) destaca que este tipo de método tem como características a empiria e a sistematização progressiva de conhecimento, de modo a levar à compreensão da lógica interna do processo em questão.

A opção por um método qualitativo surgiu a partir da compreensão da realidade como uma construção situada histórica e socialmente e, assim sendo, dotada de valores e de sentidos atribuídos por aqueles que a constituíram (Minayo, 2006). O caráter exploratório da pesquisa deve-se ao fato dela ter por objetivo proporcionar maior familiaridade com a problemática em questão, visando torná-la mais explícita e viabilizar a construção de novas hipóteses (Gil, 2008). Trata-se de uma aproximação com uma realidade até então pouco conhecida.

Em nossa investigação, realizamos entrevistas semi-estruturadas com o secretário de saúde do município, ao qual foi solicitado a indicação de outros trabalhadores que representassem o nível primário (atenção básica em saúde), secundário (atenção especializada e ambulatorial) e terciário de atenção (hospitalar). Pressupõe-se que essa rede de indicações tem relação com os trabalhadores considerados, na perspectiva do gestor municipal, como os mais aptos a abordarem o tema da saúde mental. Houve a indicação de um assistente social vinculado à Secretaria Municipal de Saúde (trabalhador A); um trabalhador da atenção primária (trabalhador B); um trabalhador do nível ambulatorial (trabalhador $\mathrm{C}$ ); e dois trabalhadores do nível terciário de atenção (hospital) (trabalhadores D e E). As entrevistas ocorreram entre o mês de dezembro de 2012 e abril de 2013, coincidindo, portanto, com o período de transição de um novo governo municipal. 
Dos seis entrevistados, três eram contratados e três concursados, sendo que três deles possuíam especialização. O tempo de atuação na área da saúde variava de 1 a 16 anos. Todos os trabalhadores eram vinculados à Secretaria Municipal de Saúde, à exceção dos dois trabalhadores do Hospital, que caracterizava-se como filantrópico.

Esta pesquisa foi aprovada pelo Comitê de Ética em Pesquisa (COMEP) da Universidade Estadual do Centro-Oeste (UNICENTRO). As entrevistas foram gravadas e transcritas, tendo sido realizadas mediante aceite dos participantes, cuja anuência ocorreu através da assinatura do Termo de Consentimento Livre e Esclarecido - TCLE.

Para a análise dos dados utilizamos o método de Análise de Conteúdo, baseado na lógica qualitativa. Conforme Minayo (2006), este método diz respeito a técnicas de pesquisa que possibilitam a replicação e validação das inferências sobre dados de um determinado contexto por meio de procedimentos científicos. A análise de conteúdo, enquanto método, torna-se um conjunto de técnicas de análise das comunicações que utiliza procedimentos sistemáticos e objetivos de descrição do conteúdo das mensagens (Bardin, 2009)

Partimos da compreensão de que o mais importante em uma comunicação não é o conteúdo manifesto da mensagem, mas o que ela expressa graças ao contexto e às circunstâncias em que se dá. Do ponto de vista operacional, a análise de conteúdo parte de uma leitura de primeiro plano das falas, depoimentos e documentos, para atingir um nível mais profundo, ultrapassando os sentidos manifestos do material (Minayo, 2006).

Com base nisso, realizamos uma leitura inicial das transcrições das entrevistas com o intuito de nos aproximarmos dos dados produzidos. Após várias leituras extensivas do material transcrito foi realizado o delineamento de temáticas, as quais foram sendo colocadas em diálogo com a literatura, a fim de produzir o movimento de análise.

\section{A ATENÇÃO EM SAÚDE MENTAL NO MUNICÍPIO}

O município onde a pesquisa foi realizada caracterizava-se como sendo de pequeno porte, com uma população na faixa de 50 a 60 mil habitantes. O município sediava uma das vinte Regionais de Saúde do Estado do Paraná, sendo referência em saúde para outros oito municípios. À época da pesquisa, os serviços especializados que prestavam atendimento em saúde mental eram dois: a ala psiquiátrica do hospital geral e uma unidade ambulatorial. $\mathrm{O}$ município sediava também um Centro de Atenção Psicossocial regional (CAPS II), que atendia oito municípios da região e do qual não fazia parte, não fazendo uso do mesmo. 
Estudo realizado por Pauluk e Zambenedetti (2013) demonstrou que, até o início da década de 1980, a atenção em saúde mental no município possuía duas vias principais: por um lado, estava atrelado a um caráter religioso e assistencialista; por outro lado, do ponto de vista profissional, os moradores com transtornos mentais eram enviados para hospitais em outros municípios ou eram atendidos pela clínica médica no Hospital localizado no município. No início da década de 1980 ocorre a implantação da Ala Psiquiátrica no Hospital localizado no município, representando a possibilidade de um tratamento especializado sem haver o deslocamento para outro município. Este será também o momento inaugural do modelo médico-hegemônico a ser consolidado nas décadas posteriores.

\section{CARACTERIZANDO O MODELO LOCAL DE ATENÇÃO EM SAÚDE MENTAL}

O ambulatório que concentrava as ações de saúde mental no município funcionava em uma Unidade Central de Saúde, que comportava, além do ambulatório, uma Unidade de Pronto-Atendimento (PA). Localizada no centro da cidade, esta unidade atendia grande parte da população, já que a atenção básica conseguia cobrir, através de suas quatro Equipes de Saúde da Família (ESFs), cerca de apenas $20 \%$ do território total do município, conforme dados do Departamento de Atenção Básica² .

Diante desta composição havia entre os profissionais da rede pública de saúde municipal, o entendimento de que além do atendimento especializado ofertado no ambulatório e no PA, aquela unidade também fazia parte da Atenção Básica, através das ações realizadas no ambulatório.

A central também tem atendimento na atenção básica, acaba atendendo os familiares e tal (trabalhador C).

É uma atenção primária, né, mas a gente não é um PSF, é uma unidade central, sabe? Funciona atenção primária por causa da clínica médica, entendeu? Faz prevenção de... faz os hipertensos, faz os diabéticos, faz tudo o que você encontra em clínica médica (trabalhador B).

Esta compreensão, como evidencia a fala acima, devia-se ao fato daquela unidade contemplar ações que cabiam à Atenção Básica, como a prevenção à hipertensão e diabetes e a busca ativa de usuários da saúde mental, citada em outro momento da entrevista. Cabe destacar o fato de o trabalhador B (trabalhador da unidade ambulatorial) ter sido indicado por

\footnotetext{
${ }^{2}$ Consulta realizada no site: http://dab.saude.gov.br/portaldab/historico_cobertura_sf.php
} 
outros profissionais entrevistados para participar da pesquisa como trabalhador do nível de Atenção Básica.

Notamos com isso, um reconhecimento do que vem a ser a Atenção Básica não pelo nível de atenção em que o serviço está situado, mas pela ação nele desenvolvida, denotando uma falta de clareza em relação ao que é nível de complexidade e o que é modelo de atenção, segundo as referências do Ministério da Saúde. Acreditamos que esta compreensão era reafirmada diante da situação de fragilização da Atenção Básica no município, que fazia com que ações que caberiam às ESFs fossem transferidas para a responsabilidade dos profissionais daquela unidade, que passavam a ser vistos como profissionais da Atenção Básica, como no caso do trabalhador B.

No âmbito da saúde mental as ações no ambulatório consistiam em consultas médicas com o psiquiatra da unidade (trabalhador F), as quais eram realizadas duas vezes por semana. $\mathrm{O}$ acompanhamento dos pacientes era feito por meio de reconsultas, que ocorriam em uma frequência média de dois a quatro meses. As consultas caracterizavam um atendimento de caráter individual e de ênfase no tratamento medicamentoso, como apontam os trabalhadores entrevistados.

A parte medicamentosa fica bem focada, sabe? (...) o atendimento mesmo, principal que é feito, é medicamentoso. (...) Às vezes o paciente tá lá com cinco tipos de medicamento e fica quinze, vinte anos tomando a mesma medicação, sabe? (trabalhador A)

Ele [médico] fala que é a cada... daqui dois meses, já deixa a receita pronta pra ele. Então ele consegue fazer um acompanhamento a cada três, quatro meses ele tá vendo esse paciente, sabe? (trabalhador B).

As falas ressaltam o caráter medicamentoso do atendimento ofertado. A receita de prescrição de medicamento pronta antes mesmo de atender o paciente é uma das expressões da reprodução de práticas unívocas, como aponta Jorge et al. (2012), centradas em poções fármaco-terápicas. A este respeito os autores comentam:

Referida hegemonia vem sendo construída na subordinação da prática clínica como dimensão social e humana da vida a uma tecnologia biopolítica de gestão da vida, concebida no biopoder, e também entendida como medicalização social que se mostra compatível e aceita na própria matriz da ciência moderna. Desse modo, conformam-se práticas clínicas na sociedade que priorizam elementos de intervenção voltados para a elucidação diagnóstica orgânica, terapêuticas medicalizantes e prioritariamente fármaco-químicas, bem como abordagens unidirecionais em que o indivíduo ali tido como adoecido deve simplesmente adaptar-se ao processo de cuidar estabelecido (Jorge et al., 2012, p.1545). 
Enquanto o atual modelo de atenção em saúde mental coloca em voga a necessidade da superação da institucionalização através da real inserção da pessoa em sofrimento psíquico na sociedade através de uma cooperação mútua, que envolva usuário, família, comunidade e profissionais de saúde, esta atuação centrada na perspectiva médica e restrita à prescrição de medicamentos tem contribuído pouco para potencializar a autonomia no modo de vida do usuário, o que acaba por levar à falência a proposta de uma plena vida social, como têm por intuito as diretrizes da atenção psicossocial.

Esta perspectiva medicamentosa de atuação apresenta-se contrária ao que compreende-se por intuito do modelo psicossocial de atenção. Para Costa-Rosa (2000) as considerações do modo psicossocial, sejam sobre a psicose ou sobre quaisquer outras problemáticas, procuram ir além de considerá-las como doença, por isso os recursos mobilizados para a atenção se propõem a ir muito além dos medicamentos, tendo de superar o modelo biomédico ${ }^{3}$ como único modelo de intervenção.

No atendimento centrado na perspectiva biomédica e ambulatorial, como bem nos coloca Goldberg (1996), o acesso ao paciente se faz pela via dos sintomas, de forma que a ação profissional ocorre como uma espécie de calibragem da medicação. A consequência deste processo de abordagem é que o profissional acaba atuando em um sistema que o coloca em contato com o paciente em intervalos de um a três meses, fazendo com que este paciente seja reduzido ao recorte pontual da consulta. Esta perspectiva de Goldberg a respeito do modelo biomédico reflete a lógica de atendimento encontrada no município de nossa pesquisa, na qual as consultas no ambulatório eram realizadas em intervalos de dois a quatro meses e tinham por intuito a renovação da receita médica. Este modo pelo qual os psicotrópicos são administrados e colocados como foco do tratamento - cabe lembrar que as receitas, como apontado pelo trabalhador $\mathrm{B}$, eram deixadas prontas antes do atendimento ser realizado - revelavam o exercício de um modelo de atenção pautado em um viés biomédico, que desconsidera a existência de um sujeito em sua integralidade, anula as dimensões subjetivas e socioculturais desta existência e o reduz previamente à necessidade do medicamento. A receita aparece aqui como símbolo da autoridade médica (Nascimento, 2012) e o medicamento como a encarnação do que Foucault chamou de tecnologias do biopoder (Decotelli et al., 2013).

\footnotetext{
${ }^{3}$ Modelo de atuação baseado na patologia, sobretudo em seus aspectos individuais e biológicos, centrado no hospital, nas especialidades médicas e no uso intensivo de tecnologia duras, desconsiderando o contexto psicossocial (Silva Júnior e Alves, 2007).
} 
Neste sentido, destacamos a necessidade e a importância de problematizar a perpetuação de um tratamento baseado em uma prática de medicamentalização, ao compreendemos, juntamente com Decotelli et al. (2013), que a medicação não produz apenas normatização, mas modos de subjetivação, de existência. Em relação ao uso de medicação, deve-se destacar que a crítica não reside sobre a medicação em si, mas sim ao fato de ela deixar de ser vista como uma entre tantas outras estratégias terapêuticas para ser vista como a única ou principal delas. A proposta do trabalho em redes de atenção, no âmbito da Reforma Psiquiátrica, é ampliar a oferta de recursos terapêuticos - medicação, escutas individuais e/ou grupais com caráter interdisciplinar, oficinas, acompanhamento terapêutico - contrastando com a realidade encontrada nesta município.

Neste modelo de atendimento pudemos localizar o que Merhy (2002) chama de modelo médico-centrado, em detrimento de uma prática de cuidado usuário-centrada. Neste primeiro, o processo de produção de atos de saúde não permite necessariamente a produção de saúde, pois se constitui como uma produção "procedimento centrada" e não "usuário centrada”. Em nome da produção de um diagnóstico, as necessidades do usuário são deixadas de lado e o foco da atuação passa a ser os próprios procedimentos na produção dos atos de saúde, neste caso a prescrição de medicamentos. Daí a necessidade de construirmos uma nova maneira de produzir saúde na rede de serviços, a partir da mudança de um modelo de atenção corporativo-centrado para um modelo usuário-centrado. Para Merhy, um imperativo se coloca neste processo: "a construção de uma prática cuidadora que tenha como eixo de sua intervenção o mundo das necessidades dos usuários" (2002, p.10), uma prática usuáriocentrada.

\section{A HEGEMONIA DO SABER MÉDICO-ESPECIALIZADO: NESSE PACIENTE EU NÃO VOU POR A MÃO}

Como apontado anteriormente, além do ambulatório, outro serviço da atenção em saúde mental no município era a ala psiquiátrica do hospital geral, que servia à internação dos usuários nos casos em que se fizesse necessário, por exemplo, em momentos de crise. O que permitia o fluxo dos pacientes entre estes dois serviços e a tentativa de estabelecer a continuidade do tratamento era o fato de que o responsável pelo atendimento destes pacientes no hospital e no ambulatório era o mesmo. Assim, o profissional que realizava as consultas no ambulatório era também o responsável pelo internamento dos pacientes no hospital. Podemos 
afirmar que o fluxo de usuários pelos serviços não seguia uma lógica institucional, pactuada entre diferentes instâncias. As decisões sobre continuidade do atendimento aos usuários de saúde mental era centralizada no trabalhador F, cabendo aos demais profissionais um papel assessório na equipe.

Não tem um local que ele [o paciente] possa ser acompanhado. Se não for o médico daqui [hospital] que faz esse acompanhamento na Secretaria da Saúde, aí seria pior (trabalhador D).

Tem uma dificuldade muito grande que a equipe de saúde, os médicos, os profissionais, eles têm a visão de que um paciente portador de transtorno metal é o paciente do trabalhador F, sabe? Então, assim, "ah é o fulano de tal". "Não, esse é paciente do trabalhador F. Eu não vou por a mão" (trabalhador A).

Estas falas revelam a personificação da atenção em saúde mental, onde a assistência tinha por referência o trabalhador F. Uma das consequências deste fato era a perpetuação do modelo médico hegemônico, como evidencia a fala de um dos trabalhadores:

Quando eu entrei aqui, saúde mental se direcionava estritamente ao trabalhador F, que é médico psiquiatra. Se falava em saúde mental, era algo muito ligado à questão da psiquiatria, né? (Trabalhador A).

Outra expressão que evidencia este modelo é o fechamento da Ala Psiquiátrica do Hospital Geral no período em que o trabalhador F está em férias. Esta hegemonia do modelo médico, onde todo o cuidado é de responsabilidade deste profissional, destoa dos fundamentos da Reforma Psiquiátrica, que apregoa que o acompanhamento terapêutico deve ser realizado por uma equipe multiprofissional. Como aponta Amarante (2007), com a ideia do trabalho em equipe, o tratamento passa a ser considerado não mais exclusivo do médico psiquiatra, mas de uma equipe com vários profissionais, fazendo com que eles passem a ter um novo protagonismo no contexto das políticas de saúde mental.

No modelo psicossocial a forma de organização deve contemplar um organograma horizontal, em que esta organização seja colocada a serviço das práticas de atenção, operacionalizando a horizontalização das relações de poder, tanto entre os trabalhadores quanto entre estes e os usuários (Costa-Rosa, 2000). A respeito desta horizontalização, o mesmo autor aponta para a distinção necessária entre poder decisório e poder de coordenação. O poder decisório é dado pelo conjunto de profissionais do serviço na reunião geral da instituição. Já o poder de coordenação é um poder dado em representação, cujas funções são coordenar as ações conjuntas e fazer com que sejam executadas em suas dimensões particulares as decisões tomadas pelo coletivo. O que se nota é, portanto, que apenas o poder 
de coordenação é significativamente marcado pela esfera do saber técnico, ou do saber-fazer. Opera-se, assim, a distinção entre fluxos decisórios e de execução - saber é diferente de poder (Costa-Rosa, 2000). O que notamos no modelo de atenção no município de nossa pesquisa, entretanto, é a perpetuação de um saber-poder médico hegemônico, que centraliza decisões e intervenções a respeito dos casos a que atende, fragilizando a proposta de interdisciplinaridade e horizontalização das relações que propõe o novo modelo. Deve-se ressaltar, no entanto, que este modelo envolve e está disseminado por uma rede de relações, já instituídas e cristalizadas no município, não havendo "culpados" ou "vítimas".

Como coloca Merhy (2002), ao invés de acontecer no interior das equipes de saúde, o trabalho do profissional se fecha no espaço físico dos consultórios. Surge daí a necessidade de um modelo assistencial centrado no usuário e na defesa radical da vida, comprometido com uma gestão mais coletiva nos processos de trabalho no interior das equipes, um trabalho multi e interdisciplinar.

Na luta pela consolidação efetiva deste modelo, faz-se necessário que atentemos para os fatores que historicamente contribuem para dificultar estes caminhos de construção de novas práticas. Ao compreendermos a campo da saúde mental como campo de forças em constante disputa, os contornos que vão delineando e desenhando as linhas de forças em seus encontros e desencontros, vão ganhando complexidade. Os desafios que se impõe à efetivação de práticas condizentes com as novas diretrizes são dotados de história e estão mergulhados neste campo de disputa.

Nardi e Ramminger (2006), ao pensar os modos de subjetivação dos trabalhadores em saúde mental apontam para três discursos que fizeram parte da história nos modos de tratar a loucura e que disputam esse campo de atuação: o discurso religioso, o discurso médico e o discurso da Reforma Psiquiátrica. Quando do surgimento do discurso da Reforma, ele passou a disputar o campo da saúde mental com os dois primeiros, mas sobretudo, ao que parece, com o discurso médico. Para Nardi e Ramminger, o discurso da Reforma propõe "um deslocamento do saber médico-psiquiátrico para a interdisciplinaridade, da noção de doença para a de saúde, dos muros dos hospitais psiquiátricos para a circulação pela cidade, ou seja, uma passagem do discurso médico para o discurso da cidadania” (2006, p.274).

Se o que vemos é um campo atravessado por estes discursos, trata-se então, de desinstitucionalizar o discurso médico hegemônico das práticas de cuidado em saúde mental. Ao compreendermos que a instituição não refere-se a um estabelecimento, mas a modos de funcionamento instituídos e, portanto, cristalizados, a ideia da desinstitucionalização passa a 
ser a de colocar em questão o que parece natural, absoluto, imóvel. Desinstitucionalizar o discurso médico significa descristalizar as práticas por ele naturalizadas e criar novos modos de relacionar-se com a loucura, novas formas de produzir o ato cuidador, processo indispensável para que avancemos no campo da saúde mental. Deve-se destacar, novamente, que o discurso biomédico não está localizado necessariamente no profissional médico, mas sim em uma rede de relações sociais, envolvendo outros profissionais, gestores e, inclusive, os próprios usuários, que muitas vezes desconhecem a possibilidade de outros modos de cuidado.

Cabe destacar, ainda, que a problematização não deve estar restrita ao modelo médico, mas a qualquer modelo que se funde no corporativismo, tomando por referência uma determinada profissão (modelo profissional-centrado) e não o sujeito em sofrimento e suas necessidades.

\section{ENTRE PONTOS E REDES}

Se, como apontamos anteriormente, a interdisicplinaridade parecia ser uma realidade muito distante de ser efetivada no interior dos serviços de saúde mental, os desafios ficavam ainda maiores ao ampliarmos a discussão para os trabalhadores dos diferentes serviços.

Através das entrevistas com os trabalhadores da ala psiquiátrica do hospital, foi possível perceber a existência de um desconhecimento em relação às ações que vinham sendo efetivadas na constituição da atenção à saúde mental no município. Os trabalhadores referiram não estarem informados a respeito da situação do CAPS no período em que foi feita a coleta dos dados desta pesquisa. Naquele momento o município não mais fazia parte do Consórcio Intermunicipal de Saúde (CIS) e estava em discussão se os usuários do município seriam atendidos no CAPS II (vinculado ao CIS) ou a possibilidade de implantação de um CAPS I, no qual apenas os usuários do município seriam atendidos.

Estão vendo a questão do CAPS, né? Mas que ainda eu não sei se tá em funcionamento. Eu, sinceramente, não sei te informar (trabalhador D).

Em outro momento da entrevista, ao serem questionados a respeito do encaminhamento de usuários para serviços de outros municípios, um dos trabalhadores respondeu:

Não sei em relação ao município como eles fazem, mas por exemplo, se o paciente chega aqui, né, e por alguma razão ele não possa ser atendido aqui no hospital, existe daí sim um contato com hospitais de fora, mas hospitais, né? (trabalhador E) 
Essas falas evidenciam uma desarticulação da rede de saúde mental. Considerando-se que o lugar da internação, no contexto da Reforma Psiquiátrica, tem caráter pontual e eventual, torna-se necessário construir pontes de acesso entre os hospitais e os serviços de saúde mental dos municípios, para que os tratamentos possam ter continuidade, evitando as situações de crise e re-internação. O problema da desarticulação entre o nível hospitalar e outros serviços é considerado um desafio em vários lugares do Brasil, não sendo este um problema de caráter unicamente local. Dias, Gonçalves, Delgado (2010) afirmam a necessidade de constituição dos chamados "leitos de atenção integral à saúde mental", os quais podem ser constituídos tanto em hospitais quanto nos Centros de Atenção Psicossocial com funcionamento 24 horas. Esse novo modo de pensar a internação compreende que ela não deve se constituir como um momento isolado no cuidado ao usuário, devendo possibilitar ao usuário a possibilidade de prosseguimento de seu cuidado. Uma das dificuldades alegadas pelos profissionais do hospital é a falta de equipes e serviços que se responsabilizem por esse cuidado nos municípios da região abrangida, produzindo a falta de referências claras para o cuidado nos municípios.

Consideramos que essas desconexões da rede não podem ser consideradas como decorrência de uma responsabilidade individual de cada trabalhador, mas sim da inexistência de uma política e um plano de saúde mental que disponha os serviços e ações de modo articulado, assim como a incipiente existência de espaços de discussão e pactuação da rede, envolvendo gestores, trabalhadores e representação de usuários. A inexistência de serviços e ações substitutivas à internação ou sua fragilidade também impediam a constituição de outras referências institucionais para a atenção em saúde mental. Ao invés de uma rede, observamos alguns pontos limitados para a constituição de uma atenção em saúde mental.

A Portaria $n^{\circ} 4.279 / 10$, que estabelece as diretrizes para a organização da Rede de Atenção à Saúde (RAS) no âmbito do Sistema Único de Saúde, define a RAS como "arranjos organizativos de ações e serviços de saúde, de diferentes densidades tecnológicas, que integradas por meio de sistemas de apoio técnico, logístico e de gestão, buscam garantir a integralidade do cuidado" (Brasil, 2010, p.4). O objetivo da Rede de Atenção à Saúde seria o de promover a integração sistêmica de ações e serviços de saúde, com o intuito de prover atenção contínua, integral, de qualidade, responsável e humanizada (Brasil, 2010).

Mais especificamente em relação à atenção em saúde mental, o Ministério da Saúde aponta como serviços constituintes da rede: o CAPS - considerados dispositivos estratégicos na organização da rede -, serviços, ações e equipes na atenção básica, os ambulatórios, as 
residências terapêuticas, os centros de convivência, os clubes de lazer, as oficinas de criação, os leitos em hospitais gerais, os serviços de atenção em regime residencial, entre outros (Brasil, 2004; 2011). Aponta ainda que, para constituir essa rede, todos os recursos afetivos (relações pessoais, familiares, amigos etc.), sanitários (serviços de saúde), sociais (moradia, trabalho, escola, esporte etc.), econômicos (dinheiro, previdência etc.), culturais, religiosos e de lazer devem ser levados em conta (Brasil, 2004).

Neste sentido, a noção de rede pressupõe a existência de diversos serviços, estratégias e ações, além da incorporação de diferentes saberes e fazeres e da integração da dimensão subjetiva e social de seus integrantes.

Neste ponto, outra questão se faz pertinente. Na mesma Portaria citada anteriormente, o Ministério da Saúde aponta que a atenção primária em saúde deve coordenar a estruturação e ordenação da rede, caracterizando-se como seu centro de comunicação. "Para cumprir este papel, a APS deve ser o nível fundamental de um sistema de atenção à saúde, pois constitui o primeiro contato de indivíduos, famílias e comunidades com o sistema(...)” (Brasil, 2010, p.11).

No município de nossa pesquisa, atrelada à incipiente rede de atenção verificamos a fragilidade da atenção primária, que cobria, como apontamos anteriormente, em torno de $20 \%$ da população. Durante as entrevistas nenhum dos profissionais citou serviços da atenção primária no atendimento em saúde mental, referenciando apenas o ambulatório e a ala psiquiátrica do hospital. Como apontou um dos trabalhadores, em relação à saúde mental a função da atenção básica restringia-se à captação dos pacientes pelas Equipes de Saúde da Família e encaminhamento destes ao ambulatório para atendimento.

Eles [atenção básica] trabalham muito pouco. É só assim: acha paciente e encaminha. (...)Todo o acompanhamento é central aqui, né? Então eles não atendem lá. É só pra localizar e encaminhar (trabalhador B).

Autores como Amarante (2007) afirmam que a radicalidade da desinstitucionalização deve ser permeada pela atenção básica em saúde, considerando-se a alta capacidade resolutiva das equipes de ESF. Como coloca o Ministério da Saúde, é a rede básica de saúde o lugar privilegiado de construção de uma nova lógica de atendimento e de relação com os transtornos mentais (Brasil, 2004). No entanto, considerando-se a configuração da rede de saúde local, tal potência da atenção básica acabava aparecendo como uma fraqueza, dado o seu baixo alcance de cobertura populacional. 
Cintando Lancetti (2006), Amarante (2007), afirma que para que a radicalidade da desinstitucionalização seja alcançada é necessário que as ESFs sejam bem treinadas na concepção mais geral da reforma psiquiátrica o que, notamos, não acontecia no município onde a pesquisa se desenvolveu.

Com esta limitação da atuação na atenção primária e consequente centralização do cuidado na Unidade de Saúde no centro da cidade, outro princípio fundamental na consolidação da rede de atenção ficava prejudicado, o de territorialização. O modelo de atenção psicossocial tem como um de seus fundamentos a estratégia de deslocar o centro de cuidado para a comunidade. A Reforma Psiquiátrica consiste no progressivo deslocamento do centro de cuidado para fora do hospital, em direção à comunidade, ou seja, no território (Brasil, 2004). Isto parece não se efetivar no município, permanecendo uma lógica de atendimento onde a porta de entrada era a atenção especializada. Referindo-se ao atendimento no ambulatório, um dos trabalhadores afirma:

Tem o problema de distância, mas assim é uma maneira de talvez amenizar o problema maior (trabalhador B).

Em que pesem as dificuldades estruturais e a inexistência de outros serviços que compusessem o quadro da atenção e pudessem contribuir para qualificar o cuidado, compreendemos, como Merhy (2002) que no espaço da micropolítica ${ }^{4}$ do processo de trabalho não cabe a noção de impotência, pois ele está sempre aberto à presença do trabalho vivo em ato, exemplificado pelo autor como a criatividade permanente do trabalhador, capaz de inventar novos processos de trabalho e abri-lo em direções ainda não pensadas. Longe de responsabilizar individualmente cada trabalhador pela estagnação e institucionalização das práticas de cuidado naquele contexto, nosso apontamento vem no sentido de atentar para as possibilidades de uma inventividade que potencializa o ato cuidador mesmo em meio às precarizações já postas. Compreendemos que mais do que pela existência dos serviços em si mesmos, a potencialidade do ato cuidador se efetiva nas relações, na dimensão micropolítica do cuidado.

Considerando-se os conceitos de 'rede' e 'território' como dois conceitos fundamentais ao tratar de atenção à saúde mental (Brasil, 2004), a fragilização do cuidado no município tornava-se evidente, visto que a lógica do trabalho em rede e a noção de território não foram citadas como parte das estratégias de atenção.

\footnotetext{
${ }^{4} \mathrm{O}$ espaço daquilo que acontece no cotidiano do fazer saúde, nas dimensões relacionais e subjetivas de cada ato em saúde.
} 


\section{FRENTE AOS DESAFIOS, QUE POSSIBILIDADES? ALGUMAS REFLEXÕES FINAIS}

Ao darmos início a esta pesquisa, tínhamos como objetivo caracterizar a rede de atenção em saúde mental existente no município. Entretanto, a partir das entrevistas realizadas, percebemos que ao invés de uma rede, existem no município alguns pontos de atenção, os quais nem sempre apresentam-se de modo articulado. Observamos um descompasso entre as propostas da Reforma Psiquiátrica e o sistema de atenção em saúde mental presente no município. Diante disto, apontamos para a necessidade de refletirmos acerca dos desafios e das dificuldades que, na singularidade de cada contexto, vão ganhando forma e traçando caminhos e descaminhos no processo de constituição da atenção em saúde metal e da consolidação do novo modelo proposto pela Reforma Psiquiátrica. É neste sentido que apontamos para um descompasso existente na trajetória da Reforma no cenário brasileiro. Se por um lado muito se avançou em alguns municípios e Estados, em outros a Reforma parece não exercer um impacto significativo, que possibilite alcançarmos as necessárias rupturas e superações de práticas, ações e modos de cuidar em direção à consolidação deste novo modelo.

O fechamento dos hospitais psiquiátricos não garante por si só a possibilidade de um cuidado efetivo. Pelo contrário, há que se colocar em análise que modos e modelos de atendimento temos proporcionado às pessoas em sofrimento psíquico e de que forma eles têm contribuído ou não para a consolidação do cuidado humanizado e integral. A Reforma não está dada a partir do fechamento dos manicômios, mas mais do que garantida pela existência ou inexistência de serviços, o que opera as possibilidades de sua concretização são os modos de produzir o cuidado na dimensão micropolítica do trabalho.

Neste percurso de consolidação do novo modelo de atenção muitos são os desafios que se fazem presentes. Dentre eles, destacamos neste momento, a forte cultura psiquiátrica e hospitalar que historicamente imperou nos modos de pensar e tratar a loucura, cujas raízes ainda constituem as propostas de intervenção no campo da saúde mental, sustentando um modelo de atendimento calcado na hegemonia do discurso biomédico. Aliados ao discurso médico-hegemônico, nosso modelo individualista de sociedade e a tendência à especialização do conhecimento apresentam-se como grandes desafios na implementação de um modelo de cuidado que tem dentre seus princípios a interdisciplinaridade, o trabalho em rede e o cuidado dos sujeitos concebidos em sua integralidade. O conceito de desinstitucionalização, neste 
contexto, mostra-se potente, pois visa disparar movimentos de ruptura com o saber instituído e cristalizado.

Neste sentido, faz-se imprescindível que, ao discutirmos modelos de atenção em saúde mental, levemos em conta os fatores históricos que contribuem para a perpetuação ou superação dos modos tradicionais de tratar a loucura. Considerar a historicidade da constituição deste campo e os fatores sociais e culturais que o permeiam mostra-se indispensável para que caminhemos no sentido de não culpabilizar os atores deste processo e, para que com isso, a partir da compreensão de uma realidade que atravessa e se coloca para além dos sujeitos em si mesmos, possamos olhar criticamente para esta realidade e propor novos modos de produção do cuidado em saúde mental, tendo em vista as diretrizes do modelo psicossocial de atenção.

Apontamos ainda, para a necessidade de construir e implementar estratégias que favoreçam a superação do binômio hospital-ambulatório e do modelo médico-centrado, que restringem a potencialidade do cuidado e apresentam-se como barreiras à efetivação do novo modelo. Para isso acreditamos ser indispensável a ruptura com a lógica especialista de cuidado e o investimento na atenção básica, no preparo das Equipes de Saúde da Família e, como propõe Merhy (2002), nas tecnologias leves de cuidado, compreendidas como as tecnologias da relação. Mais do que pensar a implantação de um ou outro serviço/ação - de modo pontual e fragmentado - é necessário planejar a atenção a partir dos diversos pontos da rede, suas funções e modos de articulação, visando constituir uma linha de cuidado e continuidade da atenção.

\section{REFERÊNCIAS}

AMARANTE, P.D.C. (1995). Loucos pela vida - A trajetória da Reforma Psiquiátrica no Brasil. Rio de Janeiro: Fiocruz.

AMARANTE, P. (2007). Saúde Mental e Atenção Psicossocial, $3^{\mathrm{a}}$ ed., Rio de Janeiro, Fiocruz.

BARDIN, L. (2009). Análise de Conteúdo. Lisboa, Portugal, Edições 70.

BRASIL. (2004). Ministério da Saúde. Saúde Mental no SUS: os Centros de Atenção Psicossocial. Brasília, DF. . (2011). Ministério da Saúde. Portaria $N^{o}$ 3.088, de 23 de dezembro de 2011. Brasília, DF.

DF. (2010). Ministério da Saúde. Portaria No 4.279, de 30 de dezembro de 2010. Brasília, . (2012). Saúde Mental em dados. Brasília: Ministério da Saúde. Ano VII, no 10. (2001). Lei 10.216. de 06 de abril de 2001. Dispõe sobre a proteção e os direitos das pessoas portadoras. 
CAMPOS, G.W.S. Subjetividade e administração de pessoal: considerações sobre modos de gerenciar o trabalho em equipes de saúde. (1997). In: MERHY, E.R.; ONOCKO, R. (orgs.) Agir em saúde - um diálogo para o público. São Paulo, Hucitec, p. 229-266.

COSTA-ROSA, A. (2000) O modo psicossocial: um paradigma das práticas substitutivas ao modo asilar. In: P. AMARANTE (ed.) Ensaios: subjetividade, saúde mental, sociedade. Rio de Janeiro, Editora Fiocruz, p.11-168.

DECOTELLI, K.M., BOHRE, L.C.T., \& BICALHO, P.P.G. (2013). A droga da obediência: medicalização, infância e biopoder: notas sobre clínica e política. Psicologia: Ciência e Profissão, 33(2), 446-459.

DESVIAT, M. (1994). A Reforma Psiquiátrica. Rio de Janeiro, Fiocruz.

DIAS, M.K.; GONÇALVES, R.W.; DELGADO, P.G. (2010) Leitos de atenção integral à saúde mental em hospital geral: configuração atual e novos desafios na política de saúde mental. In: VASCONCELOS, E.M. (org.). Desafios políticos da Reforma Psiquiátrica brasileira. São Paulo: Hucitec, p. 115 - 140.

GIL, A.C. (2008). Como elaborar projetos de pesquisa. 4. ed. São Paulo, Atlas.

GOLDBERG, J. (1996). Clínica da Psicose - um projeto na rede pública. Rio de Janeiro, Te Corá.

JORGE, M.S.B., CAMPOS, R.O., PINTO, A.G.A., \& VASCONCELOS, M.G.F. (2012). Experiências com a gestão autônoma da medicação: narrativa de usuários de saúde mental no encontro dos grupos focais em centros de atenção psicossocial. Physis: Revista de Saúde Coletiva, 22(4), 1543-1561.

LANCETTI, A.; AMARANTE, P. (2009). Saúde Mental e Saúde Coletiva. In: G.W.S. CAMPOS, et al. (eds.) Tratado de Saúde Coletiva. 2 ed. São Paulo, Hucitec.

MERHY, E. E. (2002) Saúde: a cartografia do trabalho vivo. São Paulo: Hucitec.

MINAYO, M.C.S. (2006). O desafio do conhecimento. 9.ed. São Paulo: Hucitec.

NARDI, H. C.; RAMMINGER, T. (2007). Modos de Subjetivação dos Trabalhadores de Saúde Mental em Tempos de Reforma Psiquiátrica. Physys: Rev. Saúde Coletiva, 17(2), 265287.

NASCIMENTO, M.L. (2012). Em defesa de uma gestão compartilhada da medicação em psiquiatria . Physis: Rev. Saúde Coletiva, 22(1), 275-290.

SILVA JUNIOR, A.G.; ALVES, C.A. (2007). Modelos Assistenciais em Saúde: desafios e perspectivas. In: MOROSINI M.V.G.C., CORBO A.D.A. (orgs). Modelos de atenção e a saúde da família. Rio de Janeiro, EPSJV/Fiocruz, p. 27-41.

PAULUK, L. R.; ZAMBENEDETTI, G. 'Olha, eu quero me tratar, mas eu não sou louco!': Memórias, contradições e narrativas históricas da atenção a saúde mental em Irati (PR) nas décadas de 1980 e 1990. In: II Congresso Internacional de Saúde Mental, 2013, Irati-PR.

Anais do II Congresso Internacional de Saúde Mental, 2013.

RESENDE, H. (2001). Política de saúde mental no Brasil: uma visão histórica. In: TUNDIS, S. A.; COSTA, N. R. (Org). Cidadania e Loucura: políticas de saúde mental no Brasil. $7^{\text {a }}$ ed. Petrópolis: Vozes. p. 15-74.

ZAMBENEDETTI, G.; PERRONE, C.M.; O processo de construção de uma rede de atenção em saúde mental: desafios e potencialidades no processo de reforma psiquiátrica. Physis - Revista de Saúde Coletiva, v. 18, n. 2, 2008.

\section{Marcela Pereira Rosa}

Possui formação técnica em Agroindústria pela Universidade Tecnológica Federal do Paraná UTFPR (2010) e graduação em Psicologia (2016) pela Universidade Estadual do CentroOeste - UNICENTRO-PR. Desenvolveu pesquisas e projetos nas áreas de Psicologia Social e 
Comunitária, Psicologia Escolar e Saúde Mental. Tem interesse pelas áreas de Psicologia do Trabalho e Psicologia Rural.

E-mail: marcela.pereirar@gmail.com

Endereço: Universidade Estadual do Centro-Oeste - UNICENTRO-PR - PR 153 - Km 07 Riozinho - Cx. Postal, 21- CEP 84.500-000 - IRATI - PR.

\section{Gustavo Zambenedetti}

Professor Adjunto do Departamento de Psicologia e do Programa de Pós Graduação em Desenvolvimento Comunitário (PPGDC) da Universidade Estadual do Centro-Oeste (UNICENTRO) / Campus Irati-PR. Mestre e Doutor em Psicologia Social e Institucional pela Universidade Federal do Rio Grande do Sul - UFRGS. Graduado em Psicologia pela Universidade Federal de Santa Maria - UFSM. Concluiu a Residência Integrada em Saúde, Ênfase em Dermatologia Sanitária em Saúde Coletiva pela Escola de Saúde Pública do Rio Grande do Sul - ESP/RS. Tem experiência na área de Psicologia Social/Institucional e Psicologia da Saúde, atuando principalmente nos seguintes temas: saúde mental; saúde coletiva; reforma psiquiátrica; redes de atenção em saúde; processos de estigmatização e HIVAIDS, estratégias de descentralização da atenção em HIV-Aids.

E-mail: gugazam@yahoo.com.br

Endereço: Universidade Estadual do Centro-Oeste - UNICENTRO-PR - PR 153 - Km 07 Riozinho - Cx. Postal, 21- CEP 84.500-000 - IRATI - PR. 